\title{
Identification of Isolated Salmonella enterica Serotype gallinarum Biotype Pullorum and Gallinarum by PCR-RFLP
}

\author{
Narges Cheraghchi ${ }^{1}$; Pejvak Khaki ${ }^{2}$; Soheila Moradi Bidhendi ${ }^{2, *}$; Azar Sabokbar ${ }^{1}$ \\ ${ }_{1}^{1}$ Department of Microbiology, College of Basic Sciences, Karaj Branch, Islamic Azad University, Karaj, IR Iran \\ 2 Department of Microbiology, Razi Vaccine and Serum Research Institute, Karaj, IR Iran \\ ${ }^{*}$ Corresponding author: Soheila Moradi Bidhendi, Department of Microbiology, Razi Vaccine and Serum Research Institute, P.C. 3197619751, Karaj, IR Iran. Tel: +98-2634570038/+98- \\ 9123182404, Fax: +98-2634552194, E-mail: s.bidhendi@rvsri.ac.ir \\ Received: April 05, 2014; Revised: May 31, 2014; Accepted: June 09, 2014
}

\begin{abstract}
Background: Salmonella spp. is the major bacterial pathogen in poultry and is responsible for significant economic losses of the poultry industry in many parts of the world. Among Salmonella spp., Salmonella gallinarum and Salmonella pullorum are the most common causative agents of chicken salmonellosis resulting in high mortality and morbidity.

Objectives: The aim of this study was to identify S. gallinarum and S.pullorum by using the polymerase chain reaction-restriction fragment length polymorphism (PCR-RFLP) method.

Materials and Methods: In this study, 13 samples of Salmonella, isolated from local poultry, were obtained from Razi Type Culture Collection (RTCC). For the PCR-RFLP method based on the fliC gene, extracted DNA was used as a template for amplifying of the fliC gene (197bp) using specific primers. PCR products were subjected to digestion using HinpII restriction endonuclease.

Results: For the PCR, $197 \mathrm{bp}$ fliC fragment was amplified from all 13 isolates. Ten out of 13 were S. gallinarum and the other three were $S$. pullorum. As part of the PCR-RFLP, two fragments were obtained ( $82 \mathrm{bp}$ and $115 \mathrm{bp}$ ) for all S. gallinarum, whereas no digestion was observed in S.pullorum, and $197 \mathrm{bp}$ fragment was seen.

Conclusions: PCR-RFLP with fliC gene and Hinp1I endonuclease were successfully applied to differentiate the two biotypes. The results suggested that this technique could be effective in detecting S. gallinarum and S. pullorum.
\end{abstract}

Keywords:Salmonella gallinarum; Salmonella pullorum; RFLP; Hinp1I Endonuclease

\section{Background}

Under the new naming system the Salmonella enterica serovar gallinarum is divided into biovar gallinarum ( $S$. gallinarum) and pullorum (S. pullorum), which are identified to cause fowl typhoid and pullorum disease in poultry, respectively. While fowl typhoid is a disease of mature birds, pullorum causes mortality of embryos and chicks. Infection with these pathogens is responsible for considerable economic losses in poultry production (1, 2). Among diseases of poultry, salmonellosis is of great concern and has been responsible for serious economic losses of poultry producers (3). S. gallinarum and S. pullorum are non-motile, host adapted avian pathogens belonging to Salmonella serogroup $\mathrm{D}(4,5)$. S. gallinarum and S. pullorum are very similar from the point of view of their antigenic structure; however they are responsible for distinctly different diseases in chicken $(2,6)$.

Some countries are considered free of $S$. gallinarum and S. pullorum; however, infections are still sometimes reported, and are a matter of concern for the poultry industry $(4,6)$. Salmonella control efforts are complicated due to their sporadic and uneven distribution (7). Specific characterization of Salmonella isolates is therefore extremely important in order to attribute an isolate to a previously known epidemic outbreak (5). Although conventional Kaufmann White scheme is still the only reliable method for serotyping of Salmonella, it cannot differentiate between closely related biotypes, such as $S$. gallinarum and S. pullorum $(4,5)$. Differentiation basically takes into account their biochemical characteristics. However, Biochemical characteristics take approximately five to seven days and are very time-consuming.

Recently, biochemical methods have been complemented by DNA-based molecular techniques, because of their sensitivity and specificity. Such methods include restriction fragment length polymorphism (RFLP), which is sometimes associated with PCR (PCR-RFLP), ribotyping, pulse field gel electrophoresis (PFGE) and variable number tandem repeat (VNTR) (8-10). PCR- RFLP is considered as a rapid test with good reproducibility for molecular typing in bacterial epidemiological studies (11). Many researchers have focused on flagellin genes for Salmonella subtyping because most of them possess the two structural genes ( $f l i C$ and $f l j B$ ) that contain a hypervariable central region and a conserved flanking DNA region.

Flagellin genes encode proteins that are related to the serotyping scheme (12). The hypervariable central region of Salmonella flagellin genes makes it possible to differentiate the Salmonella isolates by the PCR- RFLP tech-

Copyright (c) 2014, Ahvaz Jundishapur University of Medical Sciences; Published by Kowsar Corp. This is an open-access article distributed under the terms of the Creative Commons Attribution License, which permits unrestricted use, distribution, and reproduction in any medium, provided the original work is properly cited. 
Cheraghchi N et al.

nique. Many studies used part I of the gene that encodes flagellin $(f l i C)$ to differentiate serotypes. Most Salmonella strains have two structural genes (fliC and fliB) that encode flagellins. Non-motile strains generally exhibit these structural genes, but are unable to build up a functional flagellum $(13,14)$. S. gallinarum and S. pullorum have been reported to possess phase 1 flagellin $C$ gene $(f l i C)$ (1315). There are no data from epidemiological studies of $S$. gallinarum and S. pullorum isolates based on molecular typing in Iran. Thus these data could be helpful in this regard and also for the rapid detection of these bacteria.

\section{Objectives}

The aim of the present study was to differentiate S. gallinarum and S. pullorum isolated in Iran, based on the PCRRFLP method and the Hinp1I enzyme.

\section{Materials and Methods}

\subsection{Bacterial Strains}

S. gallinarum $(\mathrm{n}=10)$ and S. pullorum $(\mathrm{n}=3)$ isolates used in this study were from clinical samples of chickens kept at the Microbiology Department of Razi Vaccine and Serum Research Institute of Karaj (RVSRI). S. gallinarum (ATCC 9184) and S. pullorum (ATCC 9120) were used as positive controls and S. enteritidis (ATCC 13076) was used as a negative control. All isolates were cultured on MacConkey agar (Merck, Germany) for 24 hours at $37^{\circ} \mathrm{C}$.

\subsection{DNA Extraction}

Bacterial DNA was prepared as described by Paiva et al. (13) with some modifications. Briefly, for each isolate, a loopful of an overnight pure culture of bacteria was transferred into $1 \mathrm{ml}$ of tris-EDTA (TE) buffer $1 \mathrm{x}$, boiled at $95^{\circ} \mathrm{C}$ for 10 minutes then centrifuged at $17900 \times \mathrm{g}(10$ minutes, $4^{\circ} \mathrm{C}$ ), followed by addition of $1 \mu \mathrm{L}$ proteinase $\mathrm{K}$ (Fermentase, Inc., the Netherlands) to the supernatant. This mixture was directly used for the PCR.

\subsection{Amplification of the fliC Gene by PCR}

Specific primers, CTGGTGATGACGGTAATGGT (fliCF: 866885) and CAGAAAGTTTCGCACTCTCG (fliC R: 1063-1044), were used for the amplification of flagellin gene phase 1 (fliC) $(13,14)$. A reaction mixture containing, $5 \mu \mathrm{L}$ of ultrapure water (Gibco, Germany), $9 \mu \mathrm{L}$ of Primix (Ampliqon, Denmark), $2 \mu \mathrm{L}$ of DNA and $1 \mu \mathrm{L}$ of each primer, was prepared. The thermocycler was programmed with 1 cycle of $94{ }^{\circ} \mathrm{C}$ for 5 minutes, 35 three-step cycles; denaturation at $94^{\circ} \mathrm{C}$ for 1 minute, annealing at $58^{\circ} \mathrm{C}$ for 1 minute, extension at $72^{\circ} \mathrm{C}$ for 1 minute, and a final cycle at $72^{\circ} \mathrm{C}$ for 10 minutes. The PCR products were electrophoresed on $1 \%$ agarose gel for 1 hour at $60 \mathrm{~V}(16)$. The product size was compared with 100 bp DNA ladder (Fermentas, Inc. the Netherlands) after staining with ethidium bromide.

\subsection{PCR-RFLP}

The digestion solution was prepared with $10 \mu \mathrm{L}$ of the PCR product, $2 \mu \mathrm{L}$ of Hinp1I buffer (10X), $1 \mu \mathrm{L}$ of Hinp1l enzyme (Fermentas Inc. the Netherlands) and $17 \mu \mathrm{L}$ of ultrapure water (Gibco, Germany). After incubation at $37^{\circ} \mathrm{C}$ for 16 hours, RFLPs were determined by electrophoresis of the digested DNA on $2 \%$ agarose gel for 2.5 hours at $60 \mathrm{~V}$ (16). Sizes of the products were analyzed and compared with the 100 bp plus DNA ladder (Fermentas Inc. the Netherlands).

\section{Results}

\subsection{Amplification of the fliC Gene}

In this study, the $197 \mathrm{bp}$ fragment of the $\mathrm{fliC}$ gene was amplified from 10 S. gallinarum and three S. pullorum and no variation in gene size was detected according to gel electrophoresis (Figure 1).

\subsection{PCR-RFLP Analysis}

Ten S. gallinarum and three S. pullorum were analyzed. Digestion of S. gallinarum amplicons with Hinp1I yielded two bands, of 82 and $115 \mathrm{bp}$, while no change in S. pullorum amplicons was observed, since no digestion occurred (Figure 2).

Figure 1. Electrophoresis of fliC Gene amplicons From S. gallinarum and S. pullorum Samples

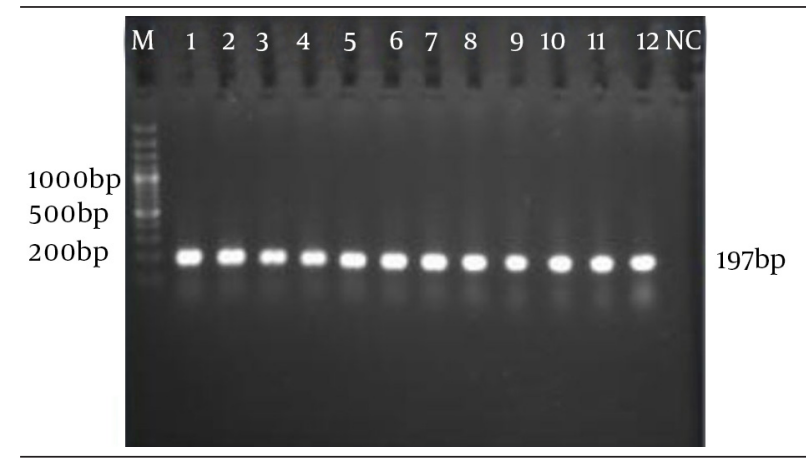

M: 100 bp marker plus DNA ladder (Fermentas Inc.). SP: lanes 1 to 3; SG: lanes 4 to 12, NC: negative control (S. enteritidis).

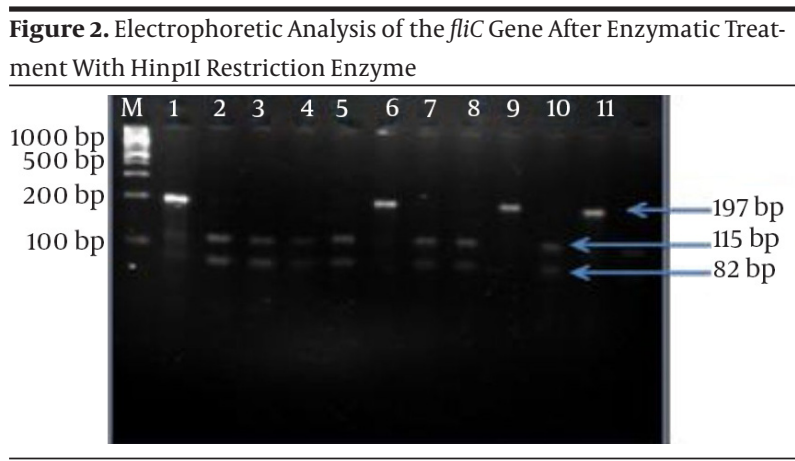


M: 100 bp marker plus DNA ladder (Fermentas Inc.); lane 1: S. pullorum positive control; lane 2: S. gallinarum positive control; lanes 3, 4, 5, 7,8,10 and 12: S. gallinarum isolates; lanes 6, 9, and 11: S. pullorum isolates.

\section{Discussion}

S. gallinarum and S. pullorum have been known as important bacterial pathogens in chicken $(2,6)$. These serovars cannot be distinguished by conventional serological methods and biochemical tests are currently complemented by molecular techniques based on fliC and fliB genes that encode flagellins (13). There has not been any research on molecular typing of S. gallinarum and S. pullorum in Iran.

In the study of Hong et al., the PCR- RFLP flagella typing scheme was successfully applied for serotype identification of 112 Salmonella isolates obtained from poultry and poultry environments (17). Also, our methods were successful in differentiating these two biotypes by PCR- RFLP. Kwon et al. worked on 41 S. pullorum and 52 S. gallinarum. They showed that PCR-RFLP with Hinp1I was successful in differentiating the two biotypes. These results suggested that the variable regions of $\mathrm{fliC}$ could be used as a genetic marker and allow differentiation of these biotypes from each other and PCR-RFLP with Hinp1I for these biotypes is a valuable tool for identification of non-motile serotypes of Salmonella (14). Our study was done on ten S. gallinarum and three S. pullorum and the same result was obtained using Hinp1I enzyme. In another study, practical application of restriction patterns of fliC gene using a mixture of endonucleases (TaqI and ScaI) to differentiate S. gallinarum and S. pullorum was performed. According to their results this method with the used enzymes was not useful to differentiate S. gallinarum from S. pullorum (15) but in our study a different enzyme, Himp1I, could differentiate these two biotypes. In the Kisiela et al. investigation, ScaI enzyme digested PCR amplicons of fimH gene. They could successfully differentiate $S$. gallinarum from $S$. pullorum (18). The results obtained from our research and theirs showed that fimH and fliC gene with restriction enzyme ScaI and Hinp 1I could differentiate S. gallinarum from S. pullorum.

In another investigation done by Paiva et al. PCR amplicons (197 bp) of 14 S. pullorum and 22 S. gallinarum that had various results on biochemical tests, were digested with the Hinp1I enzyme and the same results were obtained. In our research the bacterial isolates had different results for biochemical tests but the same pattern for PCR-RFLP (13). A study done by Menghistu et al. (8) on S. gallinarum showed three patterns in $12 \mathrm{~S}$. gallinarum isolates by PCRRFLP using the restriction enzyme AluI. They demonstrated that AluI could be used in epidemiological investigations. Our results showed that the Hinp1I enzyme could be the same as AluI in such investigation to identify $S$. gallinarum from S. pullorum. In the present study, we were able to demonstrate that the use of fliC gene restriction patterns is a useful method for allowing the differen- tiation between S. gallinarum and S. pullorum isolated in Iran; including those with atypical biochemical behavior. Therefore, our results support that this method may be adopted to differentiate S. gallinarum from S. pullorum.

Several sequences of the gene encoding phase 1 flagellin $(f l i C)$ are available $(19,20)$. The distal parts of the fliC alleles are conserved regions, making this gene in any serotype suitable for easy amplification, whereas the central region of the $\mathrm{fliC}$ gene is hyper variable, making it a target for differentiation among Salmonella serotypes $(14,15)$. S. gallinarum and S. pullorum fliC gene represent allelic variants and differ only in two codons, including 316 and 339, which shows that the Hinp1I enzyme recognizes one cleavage site in S. gallinarum (codon 316), but not in S. pullorum $(14,21)$. In the present study by using the applied technique, we were able to discriminate all the $S$. gallinarum and S. pullorum isolates. Since S. gallinarum and S. pullorum are important in industry, thus the accurate identification of them with molecular technique can be effective in this area. Our literature review in Iran showed that there isn't any publication in this field. Also our results demonstrated that PCR-RFLP with fliC gene and Hinp1I endonuclease could be effective in detecting $S$. gallinarum and S. pullorum. The result indicated that there was no limitation in this technique for differentiation of these biotypes.

\section{Acknowledgements}

The authors thank all members of the Microbiology Department of Razi Vaccine and Serum Research Institute (Karaj-Iran) for their assistance with this study.

\section{Funding/Support}

This work was fully financed with state funds from Razi Vaccine and Serum Research Institute, under grant number 12-18-18-8901-89003.

\section{References}

1. Barrow PA, Freitas Neto OC. Pullorum disease and fowl typhoid-new thoughts on old diseases: a review. Avian Pathol.2011;40(1):1-13.

2. Kang MS, Kwon YK, Jung BY, Kim A, Lee KM, An BK, et al. Differential identification of Salmonella enterica subsp. enterica serovar Gallinarum biovars Gallinarum and Pullorum based on polymorphic regions of glgC and speC genes. Vet Microbiol. 2011;147(12):181-5.

3. Lutful Kabir SM. Avian colibacillosis and salmonellosis: a closer look at epidemiology, pathogenesis, diagnosis, control and public health concerns. Int J Environ Res Public Health. 2010;7(1):89-114.

4. OIE . Fowl typhoid and pullorum disease. Manual of diagnostic tests and vaccines for terrestrial. 21th ed; 2012.

5. Gast RK. Salmonella infections, in Diseases of Poultry,. Iowa State University, Press, Ames. 1997:81-121.

6. Shivaprasad HL,. Pullorum Disease and Fowl Typhoid, in Diseases of Poultry. Iowa State Univ. 2003;Ames:568-82.

7. Jones FT. A review of practical Salmonella control measures in animal feed.J Applied Poultry Res. 2011;20(1):102-13.

8. Menghistu HT, Rathore R, Dhama K, Agarwal RK. Isolation, Identification and Polymerase Chain Reaction (PCR) Detection of Salmonella species from field materials of poultry origin. Int $J$ Microbiol Res. 2011;2(2):135-42.

9. Gallegos-Robles MA, Morales-Loredo A, Alvarez-Ojeda G, Vega PA, 
Chew MY, Velarde S, et al. Identification of Salmonella serotypes isolated from cantaloupe and chile pepper production systems in Mexico by PCR-restriction fragment length polymorphism. $J$ Food Prot. 2008;71(11):2217-22.

10. Ghaderi R, Tadayon K, Avagyan S, Khaki P, Moradi Bidhendi S, Forbes KJ, et al. The population structure of Salmonella enterica Enteritidis in Iran analyzed by multiple-locus variable-number tandem repeat analysis. Trop Anim Health Prod. 2013;45(4):889-94.

11. Taddele HM, Rathore R, Dhama K, Agarwal RK. Epidemiological Characterization of Salmonella gallinarum Isolates of Poultry Origin in India, Employing Two PCR Based Typing Methods of RAPD-PCR and PCR-RFLP. Asian J Anim Vet Adv. 2011;6(11).

12. Jong HY, Su PT, Sanpong P, Wajjwalku W, Sukpuaram T, Amavisit P. PCR-based restriction fragment length polymorphism for subtyping of Salmonella from chicken isolates. Kasetsart J. 2010;44:79-83.

13. Paiva JB, Cavallini JS, Silva MD, Almeida MA, Ângela HL, Berchieri Junior A. Molecular differentiation of Salmonella Gallinarum and Salmonella Pullorum by RFLP of fliC gene from Brazilian isolates. Brazil J Poult Sci. 2009;11(4):271-5.

14. Kwon HJ, Park KY, Yoo HS, Park JY, Park YH, Kim SJ. Differentiation of Salmonella enterica serotype gallinarum biotype pullorum from biotype gallinarum by analysis of phase 1 flagellin $\mathrm{C}$ gene (fliC). J Microbiol Methods. 2000;40(1):33-8.

15. Kilger G, Grimont PA. Differentiation of Salmonella phase 1 fla- gellar antigen types by restriction of the amplified fliC gene. $J$ Clin Microbiol.1993;31(5):1108-10.

16. Sambrook J, Russell DW. Molecular cloning: a laboratory manual (3-volume set):: Cold spring harbor laboratory press Cold Spring Harbor, New York:; 2001.

17. Hong Y, Liu T, Hofacre C, Maier M, White DG, Ayers S, et al. A restriction fragment length polymorphism-based polymerase chain reaction as an alternative to serotyping for identifying Salmonella serotypes. Avian Dis. 2003;47(2):387-95.

18. Kisiela D, Sapeta A, Kuczkowski M, Stefaniak T, Wieliczko A, Ugorski M. Characterization of FimH adhesins expressed by Salmonella enterica serovar Gallinarum biovars Gallinarum and Pullorum: reconstitution of mannose-binding properties by single amino acid substitution. Infect Immun. 2005;73(9):6187-90.

19. Chansiripornchai N, Ramasoota P, Bangtrakulnonth A, Sasipreeyajan J, Svenson SB. Application of randomly amplified polymorphic DNA (RAPD) analysis for typing avian Salmonella enterica subsp. enterica. FEMS Immunol Med Microbiol. 2000;29(3):221-5.

20. Li J, Smith NH, Nelson K, Crichton PB, Old DC, Whittam TS, et al. Evolutionary origin and radiation of the avian-adapted non-motile salmonellae. J Med Microbiol.1993;38(2):129-39.

21. Li J, Nelson K, McWhorter AC, Whittam TS, Selander RK. Recombinational basis of serovar diversity in Salmonella enterica. Proc Natl Acad Sci U S A. 1994;91(7):2552-6. 